\title{
Um Estudo sobre as Dificuldades de Inserção de Meninas na Computação
}

\author{
Sarah Barbosa de Deus, Steffany Caroline Carvalho Freire, Carina Machado de \\ Farias $^{1}$
}

Instituto Federal de Educação, Ciência e Tecnologia da Bahia - Campus Jacobina

${ }^{1}$ Pesquisadora do JaComp - Grupo de Pesquisa em Computação de Jacobina

\{sarahbarbosa04, steffanyccf99\}@gmail.com, carina.farias@ifba.edu.br

\begin{abstract}
This work presents the results of a scientific research carried out with high school graduates who sought to understand the reasons why girls do not choose higher education courses in computing. The study pointed out that boys have an advantage in basic computer knowledge and suggests that the origin of female disinterest in the area may be associated, among other factors, with the lack of stimuli from family and school.

Resumo. Este trabalho apresenta os resultados de uma pesquisa cientifica realizada com estudantes concluintes do ensino médio que buscou entender as razões que levam meninas a não escolherem cursos superiores na área de computação. $O$ estudo apontou que os meninos levam vantagem em conhecimentos básicos sobre computação e sugere que a origem do desinteresse feminino pela área pode estar associada, entre outros fatores, à falta de estímulos oriundos da família e da escola.
\end{abstract}

\section{Introdução}

O crescimento do número de cursos de computação tem sido notável no Brasil. Segundo Nunes (2017), no ano de 2001, existiam 479 cursos, tendo esse número aumentado para 2355 até o ano de 2017. Cresceram também o número de matrículas nessa área nesse mesmo período de tempo, juntamente com o número de ingressantes e concluintes. Entretanto, mesmo com o crescimento dos números em termos gerais, uma porcentagem continua pequena: a de mulheres nos cursos de Computação.

Os números de matrículas e concluintes entre o sexo feminino são muito pequenos se comparados aos dos homens. Em 2017, 143.506 pessoas ingressaram em cursos acadêmicos de computação, mas apenas 19.803 (13,8\%) eram mulheres. Um padrão parecido se dá no número de concluintes; também em 2017, foram 39.978 concluintes: 6.175 mulheres $(15,4 \%)$ [Nunes 2017]. Esses números chamam atenção por contrastarem com a quantidade de mulheres no ensino superior no Brasil que, segundo o INEP (2018), são maioria, compondo $57 \%$ dos matriculados em cursos de graduação. Outras áreas como engenharia, produção e construção também acumulam uma concentração menor de estudantes mulheres em relação aos homens, de acordo com o Censo de Educação Superior [INEP 2018].

Para Citeli (2015) a dificuldade de inserção da mulher na Computação está relacionada a inúmeros fatores, tais como a falta de divulgação de exemplos femininos motivadores na área e a sustentação de estereótipos que reforçam, não só a computação, 
mas as ciências exatas como exclusivamente para homens, designando a mulher a não se interessar pela área.

A partir da percepção do domínio masculino na área de computação, algumas iniciativas vêm sendo realizadas no Brasil nos últimos anos, buscando apresentar a área para as meninas, e dessa forma aproximá-las desta carreira e de suas tecnologias. O programa Meninas Digitais, da Sociedade Brasileira de Computação, é um dos exemplos de sucesso que se multiplicou por todas as regiões do país [FRIGO e MACIEL 2019].

Nesse contexto, foi desenvolvido o presente estudo, caracterizado como uma pesquisa explicativa, que buscou identificar fatores que contribuem ou agem como causa para a inferioridade em números da entrada de mulheres em cursos superiores da área de Informática.

A coleta dos dados se deu através de uma pesquisa de campo realizada em forma de questionário ${ }^{1}$, contendo 13 questões objetivas focadas em obter respostas que permitissem esclarecer as seguintes questões de pesquisa: 1) As meninas são estimuladas pela família e pela escola a se interessar por tecnologia? 2) As meninas possuem conhecimentos sobre tecnologias que possam despertar seu interesse pela área? 3) As meninas demonstram interesse em seguir carreira em áreas tecnológicas? Este trabalho apresenta os dados coletados durante a pesquisa, e discute os resultados observados.

\section{Apresentação da Pesquisa e Discussão dos Resultados}

O questionário produzido nesta pesquisa foi respondido por 140 estudantes, com idade entre 15 e 20 anos, de 06 escolas da cidade de Jacobina, Bahia, sendo 03 delas particulares e 03 públicas. Do total, 79 estudantes eram do sexo feminino e 61 do sexo masculino, sendo 72 de escolas particulares e 68 de escolas públicas. A pesquisa foi realizada ao longo do mês de março de 2019. Após a coleta, os dados foram tabulados em uma planilha eletrônica, a fim de facilitar a categorização do conteúdo e a interpretação das respostas.

Buscando-se compreender o estímulo dado aos jovens no núcleo familiar durante a infância, observou-se que a maioria dos entrevistados, de ambos os sexos, responderam ter tido contato com brinquedos de cunho tecnológico, embora o número de homens que respondeu Sim à pergunta foi 10,4\% maior do que o de mulheres, conforme Figura 1.

Masculino

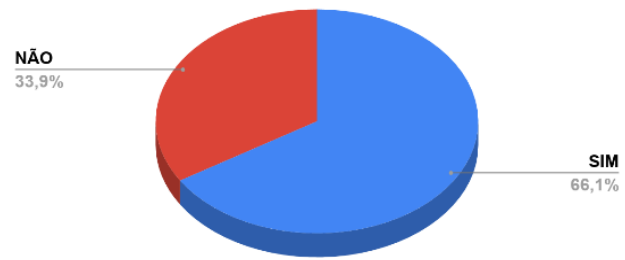

Feminino

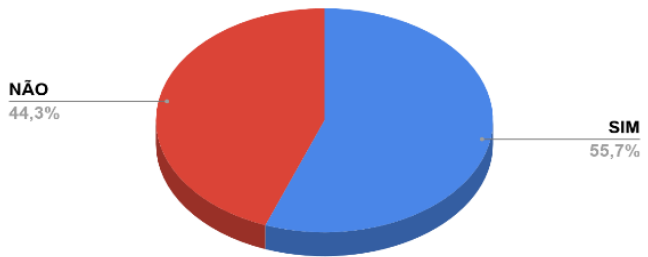

Figura 1. Respostas das meninas e meninos à pergunta: "Em sua infância, você teve acesso a brinquedos de cunho tecnológico?"

Quando o mesmo aspecto é analisado sob o contexto da natureza administrativa das escolas, percebe-se que existe uma contraposição entre as respostas das alunas de escolas públicas e particulares. O estudo aponta que as alunas de escolas particulares

\footnotetext{
${ }^{1}$ https://bit.ly/2wcXcGe
} 
apresentaram alta porcentagem de acesso à tecnologia na infância (80,0\%), em contrapartida com as de escolas públicas, em que somente $33,3 \%$ tiveram esse tipo de contato.

Ao analisar o quanto os entrevistados foram incentivados a se interessar por tecnologia ao longo de suas vidas, mais uma vez nota-se, a partir da análise da Figura 2, o estímulo para a área tecnológica voltado para os meninos, em detrimento das meninas, uma vez que $60 \%$ dos meninos entendem que o nível de estímulo que receberam para se interessar por tecnologia foi alto ou muito alto, enquanto apenas $25,3 \%$ das meninas receberam o mesmo estímulo.
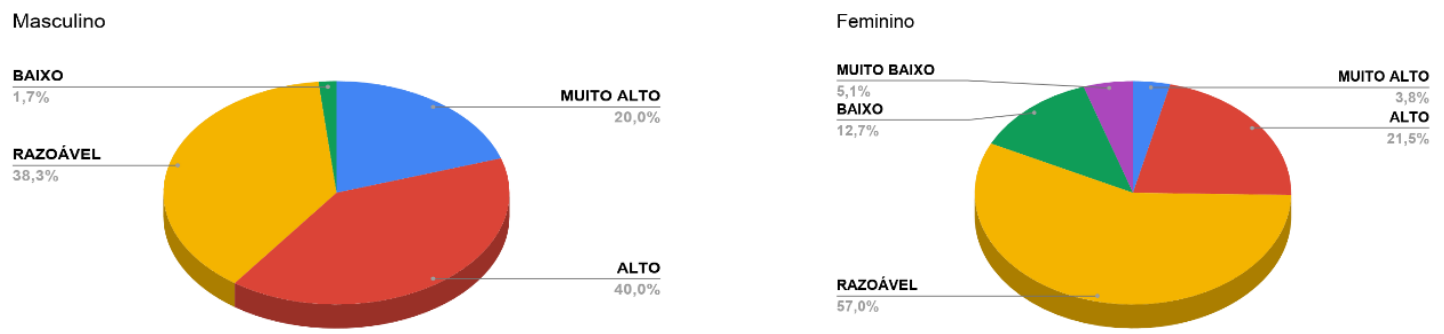

Figura 2. Respostas dos meninos e meninas à pergunta "Qual alternativa mais representa $o$ incentivo ao interesse por tecnologia que você teve ao longo da sua vida"

A partir da compreensão de que o conhecimento também pode despertar o interesse, a pesquisa buscou saber se os entrevistados possuíam conhecimentos sobre computação, a exemplo de robótica ou programação. Para tal pergunta, verificou-se que tanto meninos quanto meninas, em sua maioria não possuem domínio de conteúdos da área. Entretanto, os resultados mostram $14,7 \%$ a mais de meninos que possuem conhecimento na computação do que meninas, como apresentado na Figura 3. Um dado relevante é a origem dos conhecimentos apresentados pelos entrevistados. Enquanto $65 \%$ das meninas que possuem conhecimento em computação afirmaram ter adquirido seus conhecimentos na escola, $73 \%$ dos meninos informaram ter aprendido estudando sozinhos, fato que pode estar associado aos estímulos recebidos.

Masculino

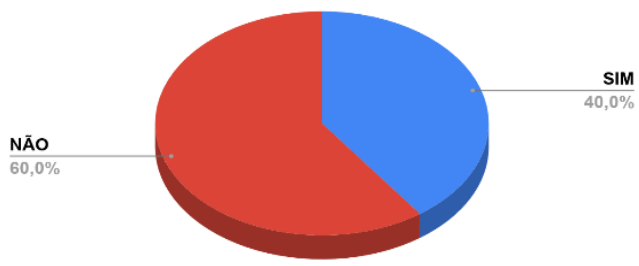

Feminino

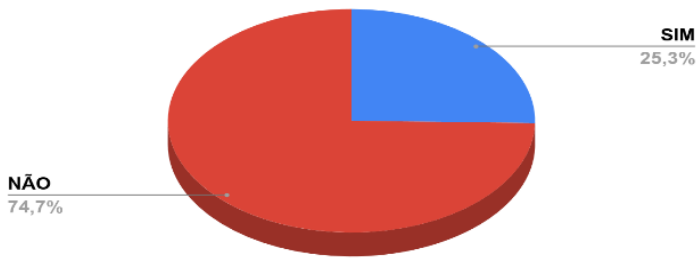

Figura 3. Repostas dos meninos e meninas à pergunta "Você possui algum conhecimento sobre a área de computação (ex. programação, robótica, hardware)?"

Por fim, o estudo buscou saber se os entrevistados tinham intenção de frequentar um curso superior no campo da computação. Mais uma vez constatou-se diferenças entres as respostas de homens e mulheres, onde a maioria dos meninos já pensaram nessa possibilidade, contrastando com a minoria das meninas, obtendo numericamente uma disparidade de $17,8 \%$ a mais de interessados para os homens, conforme a Figura 4. Outro 
dado significativo observado na pesquisa, foi que $75 \%$ das meninas que nunca pensaram em cursar a área de computação apontam a falta de conhecimento na área como um dos fatores que as levam ao desinteresse.

Feminino

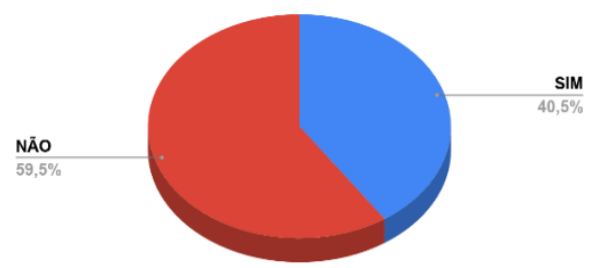

Masculino

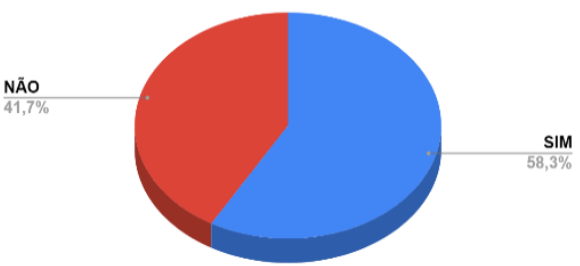

Figura 4. Repostas das meninas e meninos à pergunta "Você alguma vez pensou na possibilidade de fazer um curso superior na área de computação?"

Comparando-se os resultados das escolas públicas e privadas, verificou-se que a maioria das estudantes das escolas públicas visitadas $(56,4 \%)$ já pensaram a respeito de fazer um curso superior na área de computação, enquanto que apenas $25 \%$ das meninas das escolas particulares tiveram o mesmo pensamento, como mostrado na Figura 5. Esse é um dado intrigante uma vez que as meninas que estudam em escolas particulares tiveram maior acesso à tecnologia desde a infância, contudo, diferente do esperado, isso não contribuiu para aumentar o interesse pela área.

Escolas Públicas

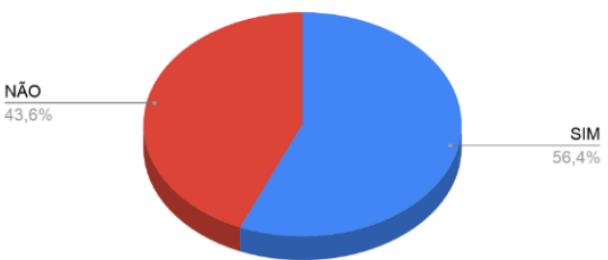

Escolas Particulares

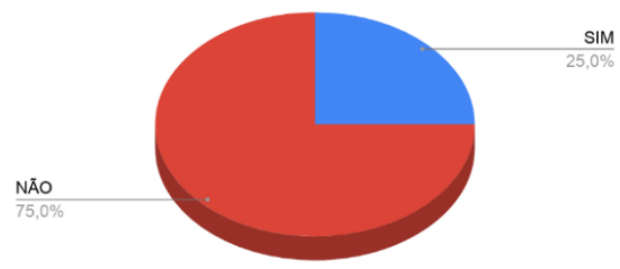

Figura 5. Respostas das meninas de escolas públicas e particulares à pergunta "Você alguma vez pensou na possibilidade de fazer um curso superior na área de computação?"

\section{Considerações Finais}

O presente trabalho apresentou os resultados observados em uma pesquisa de campo envolvendo 140 jovens, com idade entre 15 e 20 anos, que buscou compreender melhor o fenômeno dos números reduzidos de mulheres nos cursos superiores de Computação.

Compreendendo que muitos são os fatores que podem contribuir para o desinteresse feminino pela área de computação, o estudo ressaltou a escassez de estímulos oriundos da família na infância, evidenciada pela falta de acesso a brinquedos de cunho tecnológico, principalmente quando analisadas as meninas estudantes da escola pública, possivelmente devido à falta de recursos financeiros das famílias.

O estudo observou ainda que a falta de estímulos também se dá no ambiente escolar, visto que a maioria dos entrevistados informaram não ter conhecimentos específicos da área de computação, como robótica ou programação. A falta de 
conhecimento leva ao desinteresse, uma vez que não desperta a curiosidade dos jovens a conhecer a área.

Por fim, o estudo demonstrou que, embora cerca de $60 \%$ das mulheres entrevistadas não pretenda estudar computação em um curso superior, esse percentual cai para pouco mais de $40 \%$ quando analisadas isoladamente as estudantes das escolas públicas. $\mathrm{O}$ estudo indicou também que a falta de conhecimento sobre a área é um dos principais fatores apontados pelas entrevistadas para negar tal possibilidade.

É importante ressaltar que este ainda é um estudo limitado posto que não se aprofunda em outros aspectos que podem influenciar nas decisões da vida acadêmica de um jovem. Elementos sociais e econômicos, como renda salarial familiar e etnia não foram levados em consideração nessa pesquisa como possíveis agentes modificadores no processo de escolha do curso.

Haja vista a percepção do domínio masculino na área da tecnologia da informação desde um primeiro momento como estudante, fica então notável a necessidade de recursos que fomentem a atração de jovens do sexo feminino para o campo computacional. A criação de projetos que aumentem o interesse de mulheres em formação para atividades de programação, robótica e tecnologias são de grande importância para a mudança do cenário em que se encontra a área atualmente, a exemplo do Programa Meninas Digitais.

O impulsionamento em direção à tecnologia deve partir também da base familiar, quebrando os conceitos arcaicos de limitação feminina em relação ao estudo e trabalho em áreas previamente consideradas masculinas e inalcançáveis para as mulheres. A dissolução do estereótipo do profissional em computação deve ser feita através de um marketing da área voltado para todos os gêneros, que expanda os olhares sobre quem pode fazer um curso de informática, diminuindo essa escassez no número de mulheres que gostam e cursam computação.

\section{Referências}

CITELI, M. T. Mulheres nas ciências: mapeando campos de estudo. Cadernos Pagu, n. 15, p. 39-75, 2015. Disponível em: $<$ https://periodicos.sbu.unicamp.br/ojs/index.php/cadpagu/article/view/8635362>. Acesso em 10 abr. 2019.

FRIGO, L. B., MACIEL, C. Programa Meninas Digitais: Inspirando a Nova Geração. Computação Brasil - Revista da Sociedade Brasileira de Computação, Porto Alegre/RS, n. 41, p. 26-29, 2019. Disponível em: $<$ http://www.sbc.org.br/images/flippingbook/computacaobrasil/computa_41/pdf/Co mpBrasil_41.pdf $>$. Acesso em: 16 jun. 2020.

INEP. Censo de Educação Superior 2017. Ministério da Educação, 2018. Disponível em: $<$ http://portal.mec.gov.br/docman/setembro-2018-pdf/97041-apresentac-a-o-censosuperior-u-ltimo/file> Acesso em: 16 abr. 2019.

NUNES, D. J. Educação Superior em Computação, Estatísticas 2017. Sociedade Brasileira de Computação - SBC. Disponível em: < http://www.sbc.org.br/documentos-da-sbc/summary/133-estatisticas/1200-pdf-pngeducacao-superior-em-computacao-estatisticas-2017> . Acesso em: 19 abr. 2019. 